\title{
URGENSI METODE WAFA DALAM PEBAIKAN TAJWID AL-QUR'AN
}

\author{
1Ainil Maqsuri \\ 1Program Studi Pendidikan Agama Islam, IAIN Palopo \\ Email: ainilmaqsuri@gmail.com,
}

\begin{abstract}
This research discusses how the Urgency of the Wafa Method in improving the Qur'anic Tajweed at the Integrated Islamic Elementary School (SDIT) of Madani Palopo Kec. Wara Selatan. This type of research is descriptive qualitative, using normative, pedagogical, psychological, and sociological approaches. Data consisting of primary and secondary data, which data can get through observation, interviews and documentation. Then, it was analyzed by deductive, inductive and comparative techniques. The results of the study concluded that: 1) The ability to read the Koran by using tajweed in students was not satisfactory. The students still not understanding which is characterized by how to invite and read the Koran based on the rules of recitation. Based on the results, most of the students still lack understanding of how to read the Qur'an based on the rules of recitation.2) The urgency of the Wafa method in improving reading the Qur'an using tajweed is very influencing the reading and intonation of the Koran. Therefore, the wafa method is very relevant to the process of improving reading the Qur'an. 3) Obstacles of the implementation of learning recitation are the various types of wafa, there are those who have been able to read the Koran and also those who do not understand the Koran itself, while most who have been able to read the Koran are still lack of knowledge about its tajweed. The solution for these problems, the students must be discipline in using the wafa Method, the way the teacher conveys the Qur'an properly and correctly using the wafa method.
\end{abstract}

Keywords: Urgency, Wafa Method'

\begin{abstract}
Abstrak
Penelitian ini membahas tentang bagaimana Urgensi Metode Wafa Dalam Perbaikan Tajwid Al-Qur'an Di Sekolah Dasar Islam Terpadu (SDIT) Insan Madani Palopo Kec. Wara Selatan Jenis penelitian adalah deskriptif kualitatif, dengan menggunakan pendekatan normatif, pendekatan pedagogis, pendekatan psikologis, dan pendekatan sosiologis. Data yang terdiri atas data primer dan data sekunder, yang mana data tersebut dapat melalui observasi, wawancara dan dokumentasi kemudian dianalisis dengan teknik deduktif, induktif dan komparatif. Hasil penelitian menyimpulkan bahwa:1) Kemampuan baca al-Qur'an dengan menggunakan ilmu tajwid pada peserta didik masih kurang memahami ditandai dengan cara mengajak dan membaca al-Qur'an secara tertil menurut kaidah ilmu tajwid, berdasarkan hasil penelitian ini yang dilakukan maka diperoleh data bahwa sebagian besar peserta didik di sekolah dasar Islam terpadu (SDIT) insan madani Palopo masih kurang memahami cara membaca al-Qur'an berdasarkan kaidah ilmu tajwid.2) Urgensi metode wafa dalam perbaikan membaca al-Qur'an menggunakan ilmu tajwid ialah sangat berpengaruh terhadap baca dan tertil membaca al-Qur'an, oleh karena itu metode wafa sangat relevan dengan proses perbaikan membaca al-Qur'an. 3)Hambatan pelaksanaan pembelajaran ilmu tajwid adalah
\end{abstract}


metode wafa beragam jenisnya, ada yang sudah bisa membaca al-Qur'an dan ada juga yang belum memahami al-Qur'an itu sendiri, sedangkan sebagian besar yang sudah bisa membaca al-Qur'an masih kurang pengetahuan tentang tajwidnya. Solusi yang di gunakan harus disiplin dalam mengunakan Metode wafa, cara guru menyampaikan membaca al-Qur'an dengan baik dan benar menggunakan metode wafa

Kata Kunci: Urgensi dan Metode Wafa'.

\section{PENDAHULUAN}

Kemampuan peserta didik membaca al-Qur'an menjadi perhatian khusus di lembaga-lembaga pendidikan Islam, khususnya di Sekolah Dasar Islam Terpadu (SDIT) Insan Madani Palopo. Tidak sedikit peserta didik di Sekolah Dasar Islam Terpadu (SDIT) Insan Madani Palopo kurang mampu membaca al-Qur'an dengan tajwid yang baik dan benar.

Merupakan kewajiban sebagai umat Islam mengamalkan segala apa yang diperintahkan dan menjauhi segala larangannya Allah dalam kitab-Nya al-Qur'an. Untuk mengamalkan kewajiban itu sepenuhnya maka dituntuk untuk membaca dan mempelajari al-Qur'an. ${ }^{1}$

Banyak ulama yang telah menulis buku-buku mengenai membaca alQur'an tata cara dan kaidah-kaidah tajwid, tetapi sayang sangat sedikit umat Islam mampu memanfaatkan dan mengamalkan karangan-karangan pada ulama tersebut. Maka menjadi tugas yang mulia dan utamalah bagi orang tua dan guru terutama mata pelajaran al-Qur'an bertugas untuk mengajarkan ilmu tajwid kepada peserta didiknya agar dapat mempelajari, membaca huruf-huruf al-Qur'an dengan baik dan benar.

Bila dicermati ilmu tajwid memiliki keunikan tersendiri dengan ilmuilmu lain tidak hanya bermanfaat dalam memahami dan mengamalkan ajaran Islam semata tetapi juga memiliki keutamaan lain yang dapat dirasakan langsung oleh setiap umat di luar motif agama dengan adanya peran besar dalam perkembangan. Ilmu pengetahuan. Sejak masa kerasulan Muhammad hingga era globalisasi ini.

Mempelajari Al-Quran ada beberapa jenis metodenya, salah satu nya adalah wafa metode belajar al-Qur'an otak kanan, otak kanan ini memiliki beberapa sifat yang luar biasa seperti lebih fleksibel, menerima hal-hal baru yang terkadang tidak logis, imajinatif, penuh inofasi, kreatif dan dilakukan secara tidak sadar berdasarkan kebiasaan-kebisaan. Biasanya orang-orang yang lebih dominanotak kanan, cenderung akan melakukan hal-hal yang baru serta melakukan sesuatu berdasarkan pada keyakinan yang terdapat di alam bawah sadar. $^{2}$

\footnotetext{
${ }^{1}$ Amjad Qosim, Hafal al-Qur'an dalamSebulan (Solo: Qiblat Press, 2008), h. 5

${ }^{2}$ Muhammad Baihaqi, Wafa Belajar Al-Qur'an Metode Otak Kanan (Cet, I; Surabaya
} 2012), h. 4 
Pengajaran ilmu tajwid bagi peserta didik di sekolah dasar di anggap tepat. Karena masih kecil adalah masa kesuburan untuk menanamkan suatu pengetahuan bagi anak-anak (peserta didik) seperti yang telah dilakukan oleh guru mata pelajaran al-Qur'an di Sekolah Dasar Islam Terpadu (SDIT) Palopo merupakan salah satu lembaga pendidikan dasar yang berbasis agama yang turut membina peserta didiknya untuk belajar al-Qur'an dengan memulainya dari tatacara mengucapkan huruf-huruf arab (Hijaiyyah) atau berdarkan kaidah-kaidah atau tatacara ilmu tajwid.

Berdasarkan fenomena latar belakang diatas maka rumusan masalah dari pada penelitian ini yaitu:

1. Bagaimana kemampuan baca al-Qur'an ilmu tajwid pada peserta didik Sekolah Dasar Islam Terpadu (SDIT) Insan Madani Palopo?

2. Bagaimana urgensi metode wafa dalam perbaikan al-Qur'an ilmu tajwid di sekolah dasar Islam terpadu (SDIT) Insan Madani Palopo?

3. Apa hambatan dan solusi penerapan metode wafa dalam perbaikan tajwid pada peserta didik Sekolah Dasar Islam Terpadu (SDIT) Insan Madani Palopo?

Berikut beberapa penelitian terdahulu yang relevan dengan penelitian ini, seperti penelitian yang dilakukan oleh (1) Arlis tahun 2011, yang berjudul "fungsi ilmu tajwid meningkatkan kemampuan baca qur'an siswa di sdn no. 28 balla kecamatan bajo kabupaten luwu, meneliti kemampuan membaca al-Qur'an pada SDN NO 28 Balla pada umumnya baik terutama pada siswa kelas III sampai kelas VI. Kempuan ini diperoleh dari pembelajaran pendidikan agama Islam pada tingkatan kelas sebelumnya. Selain itu, adanya pada waktu lepas sekolah dan di malam hari di rumah. ${ }^{3}$, (2) penelitian yang dilakukan oleh Busaeri tahun 2009, Studi Tentang Kemampuan Baca Tulis Al-Qur'an Siswa Kelas X Madrasah Aliyah Negri (MAN) Palopo. Mengkaji tentang studi tentang kemampuan baca tulis alQur'an siswa kelas X Madrasah Aliyah Negeri Palopo diantaranya adalah faktor yang bersumber dari diri anak itu sendiri, kurangnya minat siswa untuk belajar, tidak adanya motivasi dari orang tua siswa itu sendiri, lingkungan masyarakat yang kurang mendukung dan lingkungan masyarakat yang kurang mendukung dan kurangnya perhatian orang tua. ${ }^{4}$ Penelitian pertama, dan kedua sangat menarik karena memiliki relevansi dengan penelitian ini. Namun, belum ada yang menekankan objek penelitiannya pada Urgensi Metode Wafa dalam Perbaikan Tajwid Al-Qur'an.

${ }^{3}$ Arlis, fungsi ilmu tajwid meningkatkan kempuan baca Qur'an siswa di SDN NO. 28 Balla kecamatan Bajo kabupaten luwu(Palopo; STAIN Palopo 2011)

${ }^{4}$ Busaeri, Studi Tentang Kemampuan Baca Tulis Al-Qur'an Siswa Kelas X Madrasah Aliyah Negeri (MAN ) Palopo. ( Palopo; STAIN Palopo 2009). 
Metode wafa berevolusi memberikan banyak inovasi. Metode wafa ini juga memiliki kelebihan untuk mengenalkan peserta didik pada urgensi membaca al-Qur'an melalui cerita. Metode otak kanan ini merupakan pembelajaran al-Qur'an yang sangat tepat pada anak di usia dini. Dengan model pendekatan otak kanan yang disajikan secara menarik dan sistematis menjadikan peserta didik belajar dengan mudah, cepat dan menyenangkan. Jaminan kualitasnya jelas yang dihasilkan peserta didik mampu membaca, menulis dan menghafal al-Qur'an dengan baik dan benar. Uji coba yang sudah dilakukan dilapangan membuat metode wafa ini semakin menunjukkan banyak pelajaran yang perlu disebarkan kepada peserta didik. ${ }^{5}$

Idealnya, pengajaran al-Qur'an terutama dalam aspek bacaan aksara al-Qur'an memiliki metode dan strategi tertentu. Dalam buku pedoman pengajianal-Qur'anyang di terbitkan Depertemen Agama, menyebutkan empat metode yang digunakan oleh sebagian guru dalam mengajarkan aksara al-Qur'an, yakni:

1. Metode Tarkibiyah (metode sinetik), yakni metode pengajaran membaca dari mengenal huruf hijayyah. Kemudian diberi tanda baca/ harakat, lalu disusun menjadi kalimat (kata), kemudian dirangkaikan dalam suatu jumlah (kalimat).

2. Metode sautiyyah (metode bunyi), yakni dimulai dengan bunyi huruf aksara, bukan nama-nama huruf contoh : $A a-B a-T a$ dst. Dari bunyi ini disusun menjadi satu kata yang kemudian menjadi kata atau kalimat yang teratur.

3. Metode Musyafahah (metode meniru), yakni meniru dari mulut ke mulut atau mengikuti bacaan seorang guru, sampai hafal. Selain itu baru diperkenalkan beberapa buah huruf beserta tanda baca/ harakat dari kata-kata atau kalimat yang dibacanya itu.

4. Metode Jami'ah (metode campuran), yakni metode yang menggabungkan metode-metode tersebut di atas atau $(1,2,3)$ dengan jalan mengambil kebaikan-kebaikannya disesuikan dengan situasi dan kondisi. ${ }^{6}$

Dengan demikian, dapat diketahui bahwa ada beberapa metode membaca al-Qur'an yang bisa digunakan dalam rangka menurunkan dan mengurangi tingkat buta aksara al-Qur'an. Lewat pengajian atau pembelajaran ilmu tajwid, kemampuan membaca atau melafazkan ayat-ayat al-Qur'an peserta didik Sekolah Dasar Islam Terpadu (SDIT) Palopo dapat meningkatkan kemampuan baca al-Qur'an.

\footnotetext{
${ }^{5}$ Muhammad Baihaqi, Wafa Belajar Al-Qur'an Metode Otak Kanan (Cet, I;Surabaya, 2012), h. 4

${ }^{6}$ Abdullah Asy-'ari, Pelajaran Tajwid Kaidah: Bagaimana seharusnya al-Qur'an(Cet, I; Surabaya: Apollo, t,th),h,10.
} 


\section{METODE}

Jenis penelitian ini adalah deskriptif kualitatif, yaitu data yang diperoleh dituangkan dalam bentuk kualitatif. Sebagai penelitian lapangan, penulis akan melakukan analisis data mengenai Urgensi Metode Wafa dalam Perbaikan Tajwid Al-Qur'an Di Sekolah Dasar Islam Terpadu (SDIT) Insan Madani Palopo Kec. Wara Selatan dengan memberikan pemaparan gambaran mengenai situasi yang diteliti dalam bentuk uraian. Penelitian ini dilakukan di Sekolah Dasar Islam Terpadu (SDIT) Insan Madani Palopo yang beralamat di Jalan Islamic Center I Km.4 Binturu Kota Palopo. Dalam penelitian kualitatif tidak menggunakan istilah populasi, tetapi dinamakan "social situation" atau situasi sosial yang terdiri dari tiga elemen yaitu tempat (place), pelaku (actor) atau aktivitas (activity) yang berinteraksi secara sinergis.

Dari data tersebut di atas diketahui bahwa jumlah populasi secara keseluruhan adalah 30 orang, dan populasi yang dijadikan sampel dalam penelitian ini 30 orang dengan menggunakan sampel acak. Hal ini dilakukan untuk mendapatkan data yang akurat dalam penelitian.

\section{PEMBAHASAN RUMUSAN MASALAH PERTAMA}

Kemampuan baca Al-Qur'an dengan menggunakan ilmu tajwid pada peserta didik masih kurang memahami ditandai dengan cara mengajak dan membaca Al-Qur'an secara tertil menurut kaidah ilmu tajwid, berdasarkan hasil penelitian ini yang dilakukan maka diperoleh data bahwa sebagian besar peserta didik di sekolah dasar Islam terpadu ( SDIT) Insan Madani Palopo masih kurang memahami cara membaca Al-Qur'an berdasarkan kaidah ilmu tajwid. Ilmu yang digunakan untuk, memahami cara melafazkan atau membunyikan huruf-huruf Al-Qur'an dengan baik dan benar, baik hurufhuruf itu sendiri maupun dalam satu rangkaian kata maupun kalimat. Dengan demikian yang disebut ilmu tajwid di sini adalah ilmu yang mempelajari tentang cara membaca Al-Qur'an dengan baik dan benar.

Tabel 1

Deskripsi Kemampuan Peserta Didik Di Sekolah Dasar Islam Terpadu (SDIT) Insan Madani Palopo

\begin{tabular}{cccc}
\hline No & Lancar & Kurang Lancar & Tidak Lancar \\
\hline 1 & 10 orang & - & - \\
\hline 2 & - & 3 orang & - \\
\hline 3 & - & - & 2 orang \\
\hline
\end{tabular}


Sumber data: Tata Usaha Sekolah Dasar Islam Terpadu (SIDT) Insan Madani Palopo, 2016. ${ }^{7}$

Berdasarkan data pada tabel 1 di atas, dalam kenyataan, kemampuan peserta didik sangat beragam yang mulai masuk di Sekolah Dasar Islam Terpadu (SDIT) Insan Madani Palopo ada yang sudah bisa membaca AlQur'an, ada yang masih proses belajar, dan ada yang belum sama sekali memahami Al-Qur'an itu sendiri. Hal ini merupakan suatu kendala tersendiri mengingat mereka akan belajar bersama tetapi kemampuan awal mereka berbeda. Guru harus bisa membimbing peserta didik yang belum bisa sama sekali agar mampu mengejar temannya yang lain, di samping itu harus bisa mengarahkan perserta didik yang sudah Lancar membaca Al-Qur'an agar tidak bosan kemampuannya membaca Al-Qur'an jaga tetap berkembang.

Guru yang mempunyai tugas sebagai pengajar yang membelajarkan peserta didik menciptakan suasana belajar yang menyenangkan,guru bertugas dan bertanggung jawab mentransfer ilmunya kepada peserta didik sedangkan peserta didik memiliki kepentingan belajar untuk menerima ilmu yang di transfer oleh guru yang diiringi rasa ingin tahu. Dalam proses transfer ilmu guru mempunyai strategi belajar sesuai materi yang diajarkan.

Dalam upaya mengatasi masalah peserta didik membaca Al-Qur'an sama sekali ini agar cepat tepat bisa mengejar kemampuan teman-temannya yang memang sudah mampu membaca Al-Qur'an sebelum mereka masuk di Sekolah Dasar Islam Terpadu (SDIT) Insan Madani Palopo maka diperlukan metode wafa membaca yang relatif lebih cepat dan efsien. Atas dasar inilah, metode wafa sebagai metode cepat belajar membaca Al-Qur'an ini yang coba diterapkan untuk memaksimalkan target yang ingin dicapai kurikulum di sekolah.Melihat keunikan dan kemudahan yang ditawarkan oleh metode wafa pembelajaran membaca Al-Qur'an. ${ }^{8}$

\section{PEMBAHASAN RUMUSAN MASALAH KEDUA}

Kepala sekolah SDIT Insan Madani Kota Palopo mengutarakan urgensi metode wafa dalam perbaikan membaca Al-Qur'an menggunakan ilmu tajwid ialah sangat berpengaruh terhadap baca dan ketertilan membaca Al-Qur'an, oleh karena itu metode wafa sangat relevan dengan proses perbaikan membaca Al-Qur'an. metode wafa merupakan salah satu cara mengajar mengaji yang berbasis otak kanan, pada tahun ini baru saja di terapkan

\footnotetext{
${ }^{7}$ Staf, Sekolah Dasar Islam Terpadu (SDIT) Insan Madani Palopo, wawancara, tanggal 15 Desember 2016

${ }^{8}$ Basruddin, kepala sekolah, Sekolah Dasar Islam Terpadu (SDIT)Insan Madani Palopo, wawancara, tanggal 15 Desember 2016
} 
metode wafa, banyak sekali hal baru tentang ilmu Al-Qur'an yang di ketahui oleh para guru yang mengajar.

Sebelum metode wafa di terapkan para guru memakai metode ummi, seperti halnya dengan metode wafa untuk menjadi guru Al-Qur'anyang legal harus banyak memenuhi persyaratan, lulus dimetode wafa 1,2,3,4,5,dan buku ghoribmusykilat wafa hingga tajwid dasar. Mengaji Al-Qur'antidak sekedar asal tahu dan perakteknya.Berlatih terus dengan menerapkan ilmu makhraj yang di baca yang di dapat dan menghafal banyaknya ilmu tajwid metode wafa adalah bentuk pengembangan diri, karena metode bacaan Al-Qur'an selalu bersifat dinamis, melakukan pembaharuan demi kemudahan proses pembelajaran dengan sempurnah oleh peserta didik.

Buku wafa jilid 1 : Gambar pertama Mata saya kaya roda

Huruf tunggal berharakat fathah $\mathrm{Ma}$, Ta, Sa, Ka, Ro, Da

Gambar kedua: Ada thoha bawa jala

Huruf tunggal berharakat fathah A, Da, Tho, Ha, Ba, Wa, Ja, La

Gambar ketiga: Shofa nama qota lama

Huruf tunggal berharakat fathah Sho, $\mathrm{Fa}, \mathrm{Na}, \mathrm{Ma}, \mathrm{Qo}, \mathrm{Ta}, \mathrm{La}, \mathrm{Ma}$

Gambar keempat: Dzasya Ghoza Bawa Kadho

Huruf tunggal berharakat fathah Dza, Sya, Gho, Za, Ba, Wa, Ka, Dho

Gambar kelima: Hatsa khodzo Sama Dho'a

Huruf tunggal berharakat fathah $\mathrm{Ha}$, Tsa, Kho, Dzo, Sa, Ma, Dho, 'A

Huruf sambung berharakat fathah

Buku wafa jilid 2 : pembahasan pertama yaitu Hasana-Hasani yang berbunyi "i" dan "u", pembahasan kedua Salama-Salami yang berbunyi "an" (tanwin), "in" (tanwin), "un"( tanwin), pembahasan ketiga Mama-Maaman yang berbunyi panjang 1 alif pada Fathah diikuti alif, panjang 1 alif pada Kasroh diikuti Ya sukun,panjang 1 alif pada Dhommah diikuti wawu sukun, bentuk ta marbutho, panjang 1 alif pada Fathah berdiri, Kasroh berdiri dan Dhommah terbalik, pembahasan keempat Aamanuu yang berbunyi alif yang tidak dibaca seperti "aamanuu"

Buku wafa jilid 3:gambar pertama kisah Nabi Adam A.S

1. Mim Sukun (am - im - um )

2. Lam sukun ( al - il - ul)

Gambar kedua kisah Nabi Ibrahim A.S \& Nabi Ismail A.S

Kelompok huruf jahr disukun Ar, Az, Agh, Adh, A', Ya', Ya

Gambar ketiga kisah Nabi Ibrahim A.S dan Raja Namrud

1. Sin sukun (as, is, us)

2. Kelompok huruf hams yang disukun Ats, Af, Asy, Ash, Ak, Akh, Ah, $\underline{A h}$ Gambar keempat kisah Qorun

1. Fathah diikuti wawu sukun dibaca Au (pendek)

2. Fathah diikuti ya sukun dibaca Ai (pendek) 
3. Huruf yang bertasydid membacanya ditekan

4. Alif Lam yang tidak dibaca

Buku wafa jilid 4: Gambar pertama yaitu kisah kesabaran Nabi Muhammad Saw:

1. Bacaan dengung pada nun sukun dan mim bertasydid.

2. Bacaan dengung pada nun sukun atau tanwin bertemu huruf yang 15 yaitu: Ta', Tsa', Jim, Dal, Dzal, Za', Sin, Syin, Shod, Dhod, Tho', Dzo', Fa, Qof, Kaf

Gambar kedua kisah Perahu Nabi Nuh A.S:

1. Bacaan dengung pada nun sukun atau tanwin bertemu : Ya, Nun, Mim, Wawu

2. Bacaan dengung pada nun sukun atau tanwin bertemu $B a$

3. Bacaan dengung pada mim sukun bertemu dengan Mim atau Ba' Gambar ketiga yaitu kisah Sedekah yang indah

1. Tanda layar dibaca panjang 5 harokat

2. Huruf wawu yang tidak dibaca

Gambar keempat yaitu kisah Sang ibu sejati

1. Bacaan fathu suar

2. Latihan

Buku wafa jilid 5: Gambar pertama yaitu kisah kholifah Umar r.a dan penjual susu

1. Cara mewakafkan bacaan

2. Lafad Allah dibaca tebal dan tipis

3. Mad bertemu tasydid dal kalimat dibaca panjang 6 harokat

4. Nun bertasydid yang di wakaf dibaca dengan dengung 3 harokat Gambar kedua kisah kholifah Umar r.a dan ibu memasak

1. Nun sukun atau tanwin bertemu Lam / Ro'

2. Nun sukun atau tanwin bertemu Hamzah, Ha, Kho', 'Ain, Gain Ha Gambar ketiga kisah Ali bin Abi Tholib r.a terlambat Shalat

1. Mim sukun bertemu selain Mim dan Ba'

2. Pengenalan bacaan Qalqolah pada (Ba-Ju-Di-Tho-Qo) bila di sukun

Gambar keempat kisah Nabi Yunus A.S

Tanda baca. ${ }^{9}$

Buku ghorib musykilat wafa:

1. Isymam

2. Imalah

3. Tashil

4. Nagl

${ }^{9}$ Muhammad Baihaqi, Wafa Belajar AL-Qur'an Metode Otak Kanan (Cet IV; Surabaya, 2014), h. iii 
5. Nun Wiqoyah

6. Mad dan Qoshr
a. Shifrul Mustadir
b. Shifrul Mustathil
c. Lain-lain

7. Saktah

8. Badal / Ibdal

9. Baroah

10. Rangkuman

11. Latihan

12. Qur'an Usmani

Metode wafa biasanya di awali dengan cerita, kisah Nabi dan para sahabatnya atau diawali dengan games, masuk ke praktek dan ada alat peraganya untukdi baca sama-sama dengan peserta didik di dalam kelas dan lama waktunya untuk diperaktekan kerena metode wafa memang mengeluarkan banyak energi untuk mengajarkannya, biasa sampai kewalahan guru untuk mengajarkan metode wafa ini, metode wafa memakai nada dan dia memakai lagu hijas datar,tinggi, dan rendah. ${ }^{10}$

Setelah memakai metode wafa, peserta didik lebih bersemangat belajar Al-Qur'an, tidak ada ketegangan, penuh gairah selama pembelajaran, dan serasa tidak mau berakhir saja metode wafa membuat guru dan peserta didik setia pada Al-Qur'an dengan keceriaan. Metode wafa sudah di terapkan di sekolah, peserta didik sangat mencintai gurunya. Metode ini sangat cocok untuk segala usia, terutama bagi anak-anak, keistimewaan metode ini adalah bisa membangkitkan semangat dan gemeran membaca, menghafal, memahami dan menerapkan Al-Qur'an dalam kehidupan sehari-hari. Bahkan tidak hanya itu, peserta didik juga bisa terlatih menulis teks Al-Qur'andalam bahasa Arab.

Belajar dengan metode wafa sangat mudah dan menyenangkan. Sehingga peserta didik akan menikmati proses belajar Al-Qur'an, karena sebelum peserta didik di perkenalkan dengan metode wafa para guru harus paham dulu bagaimana mengajarkan Al-Qur'an dengan menggunakan metode wafa. Administrasi seperti apa yang di perlukan untuk melihat perkembangan peserta didik dalam belajar Al-Qur'an, serta para guru juga siap memberi contoh Al-Qur'an dengan lagu hijaz salah ciri khas dari metode wafa tentunya dengan tajwid dan makhrijul huruf dengan benar. ${ }^{11}$

\footnotetext{
${ }^{10}$ Basruddin, Kepala Sekolah, Sekolah Dasar Islam Terpadu(SDIT) InsanMadani Palopo, wawancara, tanggal 15 Desember 2016

${ }^{11}$ Basruddin, Kepala Sekolah, Sekolah Dasar Islam Terpadu (SDIT) Insan Madani Palopo, wawancara, tanggal 15 Desember 2016
} 
Metode wafa berevolusi memberikan banyak inovasi. Metode wafa ini juga memiliki kelebihan untuk mengenalkan peserta didik pada urgensi membaca Al-Qur'an melalui cerita. Metode otak kanan ini merupakan pembelajaran Al-Qur'an yang sangat tepat pada anak di usia dini. Dengan model pendekatan otak kanan yang disajikan secara menarik dan sistematis menjadikan peserta didik belajar dengan mudah, cepat dan menyenangkan. Jaminan kualitasnya jelas yang dihasilkan peserta didik mampu membaca, menulis dan menghafal Al-Qur'an dengan baik dan benar. Uji coba yang sudah dilakukan dilapangan membuat metode wafa ini semakin menunjukkan banyak pelajaran yang perlu disebarkan kepada peserta didik. ${ }^{12}$

\section{PEMBAHASAN RUMUSAN MASALAH KETIGA}

Penelitian ini menemukan bahwa hambatan yang ditemukan adalah Metode wafa beragam sejeninya ada yang ada yang sudah bisa membaca AlQur'an dan ada juga yang belum memahami Al-Qur'an itu sendiri, sedangkan sebagian besar yang sudah bisa membaca Al-Qur'an masih kurang pengetahuan tentang tajwidnya. Solusi yang di gunakan harus disiplin dalam menggunakan Metode wafa, cara guru menyampaikan membaca Al-Qur'an dengan baik dan benar menggunakan metode wafa. Bahkan lagu yang dipakai sangat nampak panjang pendeknya akan terlihat lagu yang dipakainya.

Faktor kecerdasan, tingkat kecerdasan mereka berbeda-beda ada yang tinggi, ada sedang dan ada yang lambat kesannya memperlambat keberhasilan dari metode yang di gunakan karena tidak kemungkinan tingkat kecerdasan mereka sama, karena teknisnya mereka belajar di sekolah, kemudian dari sisi orang tua karena metode wafa ini didampingi orang tua, oleh karena itu orang tua melatih peserta didik di rumah bacaannya di ulang kembali karena di sekolah target kurikulum satu hari satu halaman, peserta didik harus mencapai kurikulum yang ingin dicapai di sekolah.

Metode wafa ini lebih menarik kemudian menggunakan metode otak kanan peserta didik belajar sambil bermain, kemudian ada kisah-kisahnya memang dibuat menarik supaya peserta didik tidak bosan di dalam kelas apalagi sekolah satu hari, waktunya tidak hanya di pagi hari, ada yang masuk di siang hari dan ada juga masuk ba'da duhur, di waktu siang ini membosankan untuk belajar metode wafa dan di buat lebih menarik kemudian pencapaian target juga lebih disiplin metode wafa ini lagunya juga enak di dengar.

Guru harus berkualitas menurut standarnya metode yang digunakan di sekolah. Bukti kualitas menurut standar yang menjamin seseorang dapat

\footnotetext{
${ }^{12}$ Nur Hayati, Guru Wafa, Sekolah Dasar Islam Terpadu (SDIT) Insan Madani Palopo, wawancara, tanggal 1S8 Desember 2016
} 
dikatakan sebagai guru profesional adalah selembar sertifikat. Pemerolehan sertifikat sebagai guru profesional harus melalui dan lulus uji kompetensi guru. Guru merupakan salah satu unsur terpenting dalam pendidikan. Baik buruknya kualitas pendidikan sangat ditentukan oleh standar kualitas guru. Oleh karena itu, guru perlu meningkatkan kompetensinya.

Disiplin dalam menggunakan metode wafa, bagaimana guru menyampaikan, tertib administrasinya supaya mudah diukur sampai mana tingkat pencapaiannya, tentu guru harus mempunyai kualitas lebih dalam membaca Al-Qur'an, guru sertifikasi untuk bisa menggunakan metode wafa pada sekolah ini, harus ada beberapa guru yang bisa mengkordinir Al-Qur'an dari pemilik metode wafa. Guru harus selalu dibimbing oleh kordinator AlQur'an.

\section{PENUTUP}

\section{Simpulan}

Berdasarkan uraian yang telah dikemukakan sebelumnya maka penulis menyimpulkan sebagai berikut: (1) Kemampuan baca al-Qur'an dengan menggunakan ilmu tajwid pada peserta didik masih kurang memahami ditandai dengan cara mengajak dan membaca al-Qur'an secara tertil menurut kaidah ilmu tajwid, berdasarkan hasil penelitian ini yang dilakukan maka diperoleh data bahwa sebagian besar peserta didik di Sekolah Dasar Islam Terpadu (SDIT) Insan Madani Palopo masih kurang memahami cara membaca al-Qur'an berdasarkan kaidah ilmu tajwid; (2) Urgensi metode wafa dalam perbaikan membaca al-Qur'an menggunakan ilmu tajwid ialah sangat berpengaruh terhadap baca dan ketertilan membaca al-Qur'an, oleh karena itu metode wafa sangat relevan dengan proses perbaikan membaca al-Qur'an. Metode wafa merupakan salah satu cara mengajar mengaji yang berbasis otak kanan, pada tahun ini baru saja di terapkan metode wafa, banyak sekali hal baru tentang ilmu al-Qur'an yang di ketahui oleh para guru yang mengajar. Sebelum metode wafa di terapkan para guru memakai metode ummi, seperti halnya dengan metode wafa untuk menjadi guru alQur'an yang legal harus banyak memenuhi persyaratan, lulus dimetode wafa 1,2,3,4,5,buku ghorib hingga tajwid dasar. Mengaji al-Qur'an tidak sekedar asal tahu dan perakteknya; (3) Hambatan pelaksanaan pembelajaran ilmu tajwid adalah Metode wafa beragam sejenisnya, ada yang sudah bisa membaca al-Qur'an dan ada juga yang belum memahami al-Qur'an itu sendiri, sedangkan sebagian besar yang sudah bisa membaca al-Qur'an masih kurang pengetahuan tentang tajwidnya. Solusi yang di gunakan harus disiplin dalam mengunakan metode wafa cara guru menyampaikan membaca alQur'an dengan baik dan benar menggunakan metode wafa agar mudah dipahami oleh peserta didik. Harus tertib administartasinya supaya mudah di 
ukur sampai dimana pencapaian, tentu guru harus mempunyai kualitas lebih membaca al-Qur'an, guru disertifikasi untuk bisa menggunakan metode wafa sekolah ini, harus beberapa guru bisa mengkordinir al-Qur'an dari pemilik metode wafa.

\section{Saran}

Berdasarkan kesimpulan yang telah dikemukakan di atas, maka dapat disarankan bahwa guru harus lebih professional dalam menerpakan metode wafa dalam mengajarkan siswa tingkat sekolah dasar melalui pengajaran membaca Al-Quran di dalam kelas. Hal ini akan menunjang kebijakan guru sekolah dalam mewujudkan visi dan misi yang di lembaga dan menjadikan sebagai pribadi yang mempuyai kesadaran untuk mentaati dan mematuhi peraturan di sekolah.

\section{DAFTAR PUSTAKA}

\section{Sumber Buku:}

\section{Al-Qur'an Karim}

Abdur Rahman As-sayuthi, Jalaliddin, Al-Itqan Fi'ulumil Qur'an. Jilid III; Syirkah Maktabah wa Mathtaba'ah Al-Babi Al-Halabi Wauladuhu: Mesir, 1951

Alam, Dt. Tombak. Ilmu Tajwid Populer 17x Pandai. Cet. XII; Jakarta Bumi Aksara, 2002

Arlis, Fungsi ilmu tajwid dalam meningkatkan Baca Al-Qur'an siswa Di SDN No. 28 Balla Kecamatan Bajo kabupaten Luwu Palopo STAIN Palopo 2009

Asy'ari, Abdullah, Pelajaran Tajwid Kaidah: Bagaimana seharusnya Al-Qur'an Cet. I Semarang toha putra grup 1997

Baihaqi, Muhammad, Wafa Belajar Al-Qur'an Metode Otak Kanan Cet, I; Surabaya 2012

Basalamah sholeh mahmud, Pengatar ilmu Al-Qur'an Cet. I surabaya: Apollo t.th

Bustani Al Bathrus, Qatrhul munith jilid I Baierut: shah riyadus shul, t,th

Busairi, Studi tentang baca tulis Al-Qur'an kelas x madrasah Aliyah Palopo, Palopo; STAIN Palopo 2009

Depertemen Pendidikan Nasional kamus besar Bahasa Indodenesia. Jakarta: balai pustaka, 1995

Djamarah,Syaiful Bahri, Guru danAnak Didik Dalam Interaksi Edukatif, Jakarta: RinekaCipta, 2000. 
Djaali, Psikologi Pendidikan, Ed. I. Cet. I; Jakarta: Bumi Aksara, 2007

Halim Muhammad Abdul, Memahami Al-Qur'an: Pendekatan Gaya dan Tema Cet, I; Bandung, 2002

Hamalik Oemar, Proses belajarMengajarCet.IV: Jakarta BumiAksara, 2007

Husain Sayyid Muhammad, Memahami esensi Al-Qur'an Cet,I Jakarta: Lantera, 2000

Jalaluddin H, teologi pendidikan Jakarta: PT. Raja Grafindo Persada, 2003

Jauzi Ipnul, Al-Wafa,Cet, I; Surabaya, 2011

Nana Syaudih S., R. Ibrahim, Perencanaan Pembelajaran, Cet. II; Jakarta: Rineka Cipta, 2003

Nasution S, Teknologi Pendidikan, Ed.I Cet.III; Bumi Aksara, 2005

Nizar Samsul H, Filsafat Pendidikan Islam Pendekatan Historis, Teoritis dan Praktis; Jakarta Ciputat Pers, 2002

Berbagai Pendekatan dalam Proses Belajar dan Mengajar Cet.VII; Jakarta: PT Bumi Aksara, 2000

Mujiono Dimyati, Belajar dan Pembelajaran, Cet.III; Jakarta : Bumi Aksara, 2005

Mubarakah Hamdan, Terapi Al-Qur'an, Cet,I; Jakarta: Penerbit ALIFBATA,2006

Pentashih lajnah, Mashaf Al-Qur'an, Al-Qur'anul karim Bagian Ilmu Tajwid Jakarta, 1958

Qardhawi, Yusuf, BerinteraksiDengan Al-Qur'an, Jakarta: Gema Insani Press, 2000

Qosim, Amjad, Hafal al-Qur'an dalam Sebulan, Solo: Qiblat Press, 2008

Jalaluddin Rakmat, Psikologi komunikasi, Cet. III, Bandung: PT, Remaja Rosdakarya, 2007

Samsul Nizar H, Filsafat Pendidikan Islam Pendekatan historis, teoritis dan praktis, Jakarta: Ciputat Pers, 2002

Slameto, Belajar dan Faktor-faktor yang Mempengaruhinya, Cet. IV; Jakarta: PT .RinekaCipta, 2003

S. Syamsu, Strategi Pembelajaran Jurusan Tarbiyah STAIN Palopo,2007

Shihab M. Quraish, Membumikan Al-Qur'an fungsi dan peran Wahyu dalam kehidupan manusia Cet.XXI Bandung : Mizan 2000

Shihab Umar,Kontekstualitas Al-Qur'an : kajian tematik atas ayat-ayat hukum Al-Qur'an Cet. II ; Jakarta Pemadani, 2004

Sugiono, Metode Penelitan Kuantitatif, Kualitatif dan R\&D, Cet, XIV; Bandung: Alfabeta, 2011. 
152 | Ainil Maqsuri/ IQRO: Journal of Islamic Education Vol. 1, No.2, Desember 2018. 139-152

Halaman ini sengaja dikosongkan 